\title{
EFEKTIVITAS MODEL PEMBELAJARAN TEAMS GAMES TOURNAMENT (TGT) MENGGUNAKAN MEDIA ULAR TANGGA DAN MEDIA QUESTION CARD TERHADAP HASIL BELAJAR MATEMATIKA SISWA SMA DITINJAU DARI ADVERSITY QUOTIENT (AQ) TAHUN AJARAN 2014 / 2015
}

\author{
${ }^{1}$ Yuli Hardiana, ${ }^{2}$ Tri Andari, ${ }^{3}$ Ika Krisdiana \\ ${ }^{1}$ Pendidikan Matematika, FPMIPA, IKIP PGRI Madiun \\ email: hardiana07.ha@gmail.com \\ ${ }^{2}$ Pendidikan Matematika, FPMIPA, IKIP PGRI Madiun \\ email: triandari229@yahoo.com \\ ${ }^{3}$ Pendidikan Matematika, FPMIPA, IKIP PGRI Madiun \\ email: ikakrisdiana56@gmail.com
}

\begin{abstract}
Abstrak
Tujuan penelitian adalah: 1) Untuk mengetahui apakah model pembelajara TGT dengan media Ular Tangga lebih efektif daripada dengan media Question Card terhadap hasil belajar matematika siswa SMA. 2) Untuk mengetahui apakah terdapat pengaruh Adversity Quotient siswa tipe climbers, campers dan quitters terhadap hasil belajar matematika siswa SMA. 3) Untuk mengetahui apakah terdapat interaksi antara model pembelajaran TGT berbantuan media Ular Tangga dan media Question Card dengan Adversity Quotient siswa tipe climbers, campers dan quitters terhadap hasil belajar matematika siswa SMA.Penelitian ini berbentuk penelitian kuantitatif. Penentuan sampel menggunakan teknik Simple Random Sampling dengan kelas eksperimen 1 diajar dengan model pembelajaran TGT berbantuan Ular Tangga dan kelas eksperimen 2 berbantuan Question Card. Metode penelitian menggunakan metode eksperimen semu. Teknik pengumpulan data menggunakan angket untuk data Adversity Quotient dan tes untuk data hasil belajar matematika siswa. Teknik analisis data menggunakan uji analisis variansi dua jalan sel tak sama dan uji lanjut menggunakan uji scheffe. Hasil penelitian dengan $\alpha=5 \%$ menunjukkan bahwa: 1) model pembelajaran TGT menggunakan media Ular Tangga sama efektifnya dengan model pembelajaran TGT menggunakan media Question Card terhadap hasil belajar matematika siswa $\left(F_{o b s}=2,4932<F a=4,0304\right)$. 2) Adversity Quotient memberikan pengaruh terhadap hasil belajar matematika siswa $\left(F_{o b s}=3,7166>F a=3,1788\right)$. Hasil belajar siswa yang memiliki Adversity Quotient tipe climbers tidak jauh berbeda dengan tipe campers, hasil belajar siswa yang memiliki Adversity Quotient tipe climbers lebih baik daripada tipe quitters, dan hasil belajar sswa yang memiliki Adversity Quotient tipe campers tidak jauh berbeda dengan tipe quitters 3) Tidak terdapat interaksi antara penggunaan model pembelajaran TGT berbantuan media Ular Tangga dan media Question Card dengan Adversity Quotient terhadap hasil belajar siswa $\left(F_{o b s}=1,0669<F a=3,1788\right)$.
\end{abstract}

Kata Kunci: Adversty Quotient (AQ), Teams Games Tournament (TGT), Ular Tangga, Question Card.

\section{PENDAHULUAN}

Matematika merupakan salah satu disiplin ilmu yang perlu diajarkan kepada semua peserta didik mulai dari sekolah dasar, sekolah menengah hingga perguruan tinggi. Menurut Brewer (dalam Pratiwi, 2012: 109) matematika adalah cara untuk melihat dunia dan pengalaman-pengalaman di dalamnya.
Kehadiran matematika tidak hanya bermanfaat dalam dunia pendidikan guna membantu bidang studi lain seperti akutansi, perpajakan, fisika dan kimia, tetapi juga sangat bermanfaat dalam berbagai aktivitas kehidupan seperti menghitung, berdagang dan memecahkan masalah sehari-hari, serta membantu siswa mengembangkan 
kemampuan berpikir. Marti (dalam Sundayana, 2014: 2) mengemukakan bahwa, meskipun matematika dianggap memiliki tingkat kesulitan yang tinggi, namun setiap orang harus menpelajarinya karena merupakan sarana untuk memecahkan masalah sehari-hari. Meskipun demikian masih banyak siswa yang tidak menyukai mata pelajaran matematika.

Berdasarkan pengalaman peneliti dalam Praktik Pengalaman Lapangan (PPL) yang dilaksanakan pada bulan September sampai Desember 2014, banyak ditemui siswa sudah menyerah dan merasa tidak mampu menguasai materi yang akan diajarkan sebelum kegiatan pembelajaran dilaksanakan. Sehingga siswa kurang berminat mengikuti pembelajaran matematika dengan sungguhsungguh. Selain itu berdasarkan wawancara yang dilakukan terhadap guru matematika di MAN 2 Madiun, permasalahan yang dialami tidak jauh berbeda. Ketika guru mengajar, masih ada beberapa siswa yang masih berbicara sendiri dengan temannya, menggunakan handphone, dan ada juga yang diam tapi tidak memahami dengan apa yang disampaikan guru. Namun tidak semua siswa bersikap demikian, masih ada siswa yang memperhatikan.

Selain minat siswa yang kurang, pembelajaran yang monoton membuat siswa merasa jenuh. Pembelajaran yang biasa dilakukan hanyalah kegiatan siswa yang mendengarkan penjelasan guru dan mengerjaakan soal-soal yang terdapat pada bahan ajar, LKS atau yang hanya ditulis di papan tulis. Hal tersebut jelas dapat mengganggu proses belajar dan tujuan pembelajaran tidak dapat terlaksana dengan baik. Akibatnya siswa tidak dapat memahami apa yang dijelaskan oleh guru dan memperoleh hasil belajar yang tidak memuaskan.

Berdasarkan permasalahan di atas, agar siswa lebih antusias dalam pembelajaran matematika diperlukan adanya pembelajaran yang menyenangkan bagi mereka. Pembelajaran yang menyenangkan dapat dilakukan dengan berbagai cara, salah satunya adalah memilih model pembelajaran yang inovatif. Salah satu model pembelajaran yang inovatif dan dapat menarik minat belajar siswa adalah model pembelajaran kooperatif tipe Teams Games Tournament (TGT).

Teams Games Tournament (TGT) adalah suatu tipe pembelajaran kooperatif yang menempatkan siswa dalam kelompokkelompok belajar yang beranggotakan 4 sampai 6 orang siswa yang memiliki kemampuan, jenis kelamin, dan suku atau ras yang berbeda. Sehingga siswa dapat saling membantu dalam menyelesaikan permasalahan pembelajaran yang dihadapi. Hasil penelitian terdahulu yang menunjukkan bahwa penggunaan model pembelajaran kooperatif tipe TGT mampu meningkatkan hasil belajar siswa adalah penelitian Ryan Christanto (2013), menunjukkan bahwa hasil belajar siswa dengan model pembelajaran kooperatif tipe Teams Games Turnament (TGT) lebih tinggi daripada hasil belajar siswa dengan pembelajaran konvensional pada mata pelajaran TIK kelas $\mathrm{X}$ di SMA Negeri 1 Piyungan tahun ajaran 2012/2013.

Menurut Taniredja (2014: 72-73) kelebihan pembelajaran kooperatif tipe Teams Games Tournament (TGT) adalah sebagai berikut.

a) Dalam kelas kooperatif, siswa memiliki kebebasan untuk berinteraksi dengan menggunakan pendapatnya.

b) Rasa percaya diri siswa menjadi lebih tinggi.

c) Perilaku mengganggu siswa lain menjadi lebih kecil.

d) Motivasi belajar siswa bertambah

e) Meningkatkan kebaikan budi, kepekaan, toleransi antara siswa dengan siswa dan antar siswa dengan guru.

Selain pemilihan model pembelajaran yang inovatif, cara mengajar yang menyenangkan perlu didukung dengan adanya media pembelajaran yang menarik perhatian siswa, sehingga siswa bersungguhsungguh dalam mengikuti pembelajaran 
matematika dan dapat meningkatkan hasil belajar. Salah satu pembelajaran yang menyenangkan adalah belajar sambil bermain. Bermain menurut Brewer (dalam Pratiwi, 2012: 110) adalah kegembiraan, sebuah kegiatan yang menyenangkan ketika melakukannya, bebas dari paksaan atau tekanan luar, spontan dilakukan dengan sukarela.

Menurut Santrock (dalam Pratiwi, 2012: 110) permainan ialah suatu kegiatan yang menyenangkan yang dilaksanakan untuk kepentingan kegiatan itu sendiri. Salah satu media yang dapat diaplikasikan dalam belajar sambil bermain adalah Ular Tangga. Ular tangga adalah permainan yang dapat dimainkan oleh 2-4 orang dengan menggunakan bidak dan dadu untuk mencapai finish dengan melewati hambatan ular dan bantuan tangga. Penelitian yang menunjukan model pembelajaran kooperatif Tipe Teams Games Tournament dengan permainan Ular Tangga efektif dalam pembelajaran adalah penelitian dari Arief Pratama Sam (2013), hasil pengolahan data yang diperoleh setelah dianalisis menunjukkan bahwa media Ular Tangga memberikan pengaruh terhadap hasil belajar kimia SMA Negeri 1 Hamparan Perak.

Media lain yang dapat digunakan pada model pembelajaran kooperatif tipe Teams Games Tournament selain media Ular Tangga adalah Quostions Card (kartu soal). (Febrina dkk, 2013: 157) Penggunaan media kartu soal (Question Card) dapat disebut sebagai sebuah permainan dalam suatu pembelajaran yang akan menghilangkan kejenuhan dan menciptakan suasana yang kompetitif. Berdasarkan hasil penelitian Dina Prasetyaningrum (2013), menunjukkan bahwa penggunaan model pembelajaran Teams Games Tournament (TGT) disertai media kartu soal memberikan hasil prestasi lebih tinggi dibandingkan penggunaan metode pembelajaran Teams Games Tournament (TGT) disertai media roda impian pada materi Hidrokarbon.
Selain model pembelajaran yang menyenangkan dan media yang menarik, tingkat Adversity Quotient (AQ) juga berpengaruh tehadap minat belajar siswa untuk mencapai hasil belajar matematika yang memuaskan. Hasil penelitian yang menujukkan adanya pengaruh Adversity Quotient (AQ) terhadap hasil belajar siswa adalah penelitian Anissa Dwi Ratna Aulia (2014), menunjukkan bahwa kecerdasan adversitas berpengaruh positif terhadap hasil belajar siswa pada mata pelajaran ekonomi kelas XI IPS SMA Negeri di Kota Bandung.

Sikap beberapa siswa yang tidak mempunyai kemauan mengerjakan latihan soal yang diberikan oleh guru dikarenakan siswa merasa tidak bisa mengerjakannya menunjukkan bahwa mereka mempunyai Adversity Quotient yang tipe campers bahkan quitters. Bahkan siswa cenderung menerima hasil belajar yang diperoleh apa adanya tanpa ada keinginan untuk meningkatkan. Namun tidak semua siswa seperti itu, masih ada beberapa siswa yang tetap antusias mengikuti pembelajaran matematika dengan sungguh-sungguh meskipun mempunyai tingkat pemahaman yang kurang. Dan tetap berusaha untuk mengerjakan soal latihan dari guru meskipun mengalami kesulitan. Hal ini menunjukkan bahwa siswa tersebut mempunyai Adversity Quotient tipe climbers.

Sudarman (2012), menyebutkan bahwa Adversity Quotient (AQ) adalah kecerdasan mengatasi kesulitan. Siswa yang memiliki AQ tinggi disebut siswa tipe climber. Siswa tipe climber gigih, ulet, dan tabah dalam menghadapi kesulitan. Mereka selalu berusaha mencari jalan keluar penyelesaian jika menghadapi kesulitan. Mereka tidak pernah membiarkan ada sesuatu yang menghalangi cita-citanya. Sehingga AQ sangat diperlukan siswa dalam belajar matematika.

Berdasarkan uraian yang telah dikemukakan di atas, perbandingan dari model pembelajaran TGT menggunakan media Ular Tangga dan Question Card dapat 
dijadikan bahan kajian yang dapat memberikan inovasi bagi guru mata pelajaran matematika dalam kegiatan pembelajaran.

\section{METODE PENELITIAN}

Penelitian ini dilakukan di kelas $\mathrm{X}$ MAN 2 Madiun tahun ajaran 2014 / 2015 dengan pokok bahasan statistika. Pengambilan sampel dilakukan dengan teknik Simple Random Sampling dan diperoleh kelas X MIA 4 sebagai kelas eksperimen 1 yang diberi pembelajaran dengan Teams Games Tournament (TGT) menggunakan media Ular Tangga dan kelas $\mathrm{X}$ MIA 1 sebagai kelas eksperimen 2 yang diberi pembelajaran dengan Teams Games Tournament (TGT) menggunakan media Question Card.

Metode penelitian yang digunakan adalah metode eksperimen semu. Arifin (2012: 74) menyebutkan bahwa tujuan dari eksperimen semu adalah untuk memprediksi keadaan yang dapat dicapai melalui eksperimen yang sebenarnya, tetapi tidak ada pengontrolan dan/atau manipulasi terhadap seluruh variabel yang relevan. Peneliti menggunakan metode ini karena peneliti ingin mengadakan eksperimen atau percobaan untuk mengetahui akibat/efektivitas dari model pembelajaran Teams Games Tournament (TGT) menggunakan media Ular Tangga dengan model pembelajaran Teams Games Tournament (TGT) menggunakan media Question Card terhadap hasil belajar matematika siswa SMA kelas X MAN 2 Madiun semester genap tahun ajaran 2014/2015, serta untuk mengetahui model yang lebih baik dalam meningkatkan hasil belajar matematika siswa.

Variabel dalam penelitian ini terdiri dari dua variabel yaitu variabel bebas yang terdiri atas dua kategori yaitu: 1) model pembelajaran TGT menggunakan media Ular Tangga dan Question Card, dan 2) Adversity Quotient serta variabel terikat yaitu hasil belajar.
Metode yang digunakan untuk mengumpulkan data dalam penelitian ini adalah metode tes berupa tes hasil belajar berbentuk pilihan ganda sebanyak 20 butir soal, kuesioner (angket) berupa angket Adversity Quotient yang berjumlah 20 butir pernyataan dan metode dokumentasi berupa nilai Ulangan Tengah Semester (UTS) matematika kelas eksperimen 1 dan kelas eksperimen 2.

Analisis data pada penelitian ini meliputi analisa deskriptif dan analisa inferensial. Analisa deskriptif dilakukan dengan menyajikan data melalui tabel distribusi frekuensi, dan histogram. Analisa inferensial digunakan untuk menguji hipotesis. Untuk menguji hipotesis digunakan analisis variansi (anava). Sebelum melakukan uji statistik anava, peneliti melakukan uji pendahuluan berupa uji keseimbangan, uji normalitas, dan uji homogenitas dengan menggunakan data nilai Ulangan Tengah Semester (UTS) matematika serta uji prasyarat anava berupa uji normalitas dan uji homogenitas dengan menggunakan data nilai hasil belajar matematika siswa

\section{HASIL DAN PEMBAHASAN}

Data awal yang digunakan yaitu data nilai Ulangan Tengah Semester (UTS) dari dua kelas yaitu kelas X MIA 4 sebagai kelas eksperimen 1 dan kelas X MIA 1 sebagai kelas eksperimen 2. Data deskripsi sebelum diberi perlakuan ditunjukkan pada tabel berikut.

Tabel 1 Data Awal Hasil Belajar Siswa

\begin{tabular}{|c|c|c|c|c|}
\hline \multirow{2}{*}{ Kelompok } & \multirow{2}{*}{$\begin{array}{c}\text { Jumlah } \\
\text { Siswa }\end{array}$} & \multicolumn{3}{|c|}{ Nilai Hasil } \\
\cline { 3 - 5 } & & Maksimal & Minimal & Mean \\
\hline Eksperimen 1 & 33 & 80 & 30 & 58,18182 \\
\hline Eksperimen 2 & 33 & 80 & 20 & 52,12121 \\
\hline
\end{tabular}

Hasil analisis uji kesamaan rataan atau uji- $t$ untuk kelas $\mathrm{X}$ MIA 4 dan kelas $X$ MIA 1 dengan taraf signifikansi $\alpha=5 \%$, ditunjukkan pada tabel berikut. 
Tabel 2 Rangkuman Uji Keseimbangan

\begin{tabular}{|c|c|c|c|c|c|}
\hline Kelas & $\frac{\text { rewer }}{\kappa}$ & $\boldsymbol{t}_{\text {hitung }}$ & $\boldsymbol{t}_{\text {tabel }}$ & $\begin{array}{c}\text { Keputusan uji } \\
\mathbf{t}_{\text {tabel }}>\boldsymbol{t}_{\text {hitung }}\end{array}$ & Kesimpulan \\
\hline $\begin{array}{c}\text { Eksperimen } \\
1\end{array}$ & 58,18182 & \multirow{2}{*}{1,7114} & 1,960 & $\mathrm{H}_{\ominus}$ Diterima & $\begin{array}{l}\text { kedua kelas } \\
\text { mempunyai } \\
\text { kemampuan } \\
\text { yang sama }\end{array}$ \\
\hline $\begin{array}{c}\text { Eksperimen } \\
2\end{array}$ & 52,12121 & & & & \\
\hline
\end{tabular}

Berdasarkan tabel di atas berarti keputusan uji adalah terima $H_{0}$ artinya kedua kelas mempunyai kemampuan yang sama. Uji normalitas pada penelitian ini menggunakan metode Lilliefors dengan taraf signifikansi $\alpha=5 \%$. Rangkuman hasil analisis data untuk uji normalitas disajikan pada tabel berikut.

Tabel 3 Rangkuman Uji Normalitas Sampel

\begin{tabular}{|c|c|c|c|c|}
\hline Kelas & $4^{1010}$ & $L_{\text {tabel }}$ & $\begin{array}{c}\text { Keputusan uji } \\
L_{\text {tabel }}>L_{\text {maks }}\end{array}$ & Kesimpulan \\
\hline Eksperimen 1 & 0,1453 & 0,1542 & $\mathrm{H}_{\mathrm{e}}^{\bar{E}}$ Diterima & $\begin{array}{c}\text { Berdistribus } \\
\text { Normal }\end{array}$ \\
\hline Eksperimen 2 & 0,1466 & 0,1542 & $\mathrm{H}_{\Delta}^{-}$Diterima & $\begin{array}{c}\text { Berdistribus } \\
\text { Normal }\end{array}$ \\
\hline
\end{tabular}

Hasil analisis uji homogenitas untuk kelas $\mathrm{X}$ MIA 4 dan kelas X MIA 1 menggunakan uji-F dengan taraf signifikansi $\alpha=5 \%$, ditunjukkan pada tabel berikut.

Tabel 4 Rangkuman Uji Homogenitas

\begin{tabular}{|c|c|c|c|c|c|}
\hline Kelas & $\begin{array}{l}\text { a- } \\
s^{a}\end{array}$ & $\begin{array}{l}5- \\
\text { nims }\end{array}$ & rioni & $\begin{array}{r}\text { Keputusan uji } \\
F_{\text {hitung }}<F_{\text {tabel }}\end{array}$ & kesimpulan \\
\hline Eksperimen 1 & 195,590909 & \multirow{2}{*}{1,1050} & \multirow{2}{*}{1,8044} & \multirow{2}{*}{${ }_{\text {set Diterima }}$} & \multirow{2}{*}{$\begin{array}{l}\text { variansi populasi } \\
\text { homogen }\end{array}$} \\
\hline Eksperimen 2 & 217,234848 & & & & \\
\hline
\end{tabular}

Berdasarkan tabel tersebut berarti keputusan uji adalah terima $H_{0}$ artinya tidak terdapat perbedaan variansi antara kedua kelas (variansi populasi homogen).

Data akhir nilai hasil belajar matematika yang akan digunakan pada uji prasyarat dan uji anava disajikan dalam tabel sebagai berikut.

\begin{tabular}{lcccc}
\multicolumn{3}{c}{ Tabel 5 Data Akhir Hasil Belajar Matematika Siswa } \\
\hline \multirow{2}{*}{$\begin{array}{l}\text { Model Pembelajaran } \\
\text { Kooperatif }\end{array}$} & $\begin{array}{c}\text { jumlah } \\
\text { Siswa }\end{array}$ & & \multicolumn{3}{c}{ Nilai Hasil } \\
\cline { 4 - 5 } & & Maksimal & Minimal & Mean \\
\hline $\begin{array}{l}\text { Tipe TGT dengan } \\
\text { media Ular }\end{array}$ & 28 & 95 & 75 & 83,92857 \\
Tangga & 31 & 100 & 60 & 80,48387 \\
\hline $\begin{array}{l}\text { Tipe TGT dengan } \\
\text { media Question } \\
\text { Card }\end{array}$ & 31 & & & \\
\hline
\end{tabular}

Uji prasyarat analisis variansi (anava) berupa uji normalitas menggunakan metode Lilliefors dengan taraf signifikansi $\alpha=5 \%$. rangkuman uji normalitas model pembelajaran disajikan pada tabel 6 dan uji normalitas Adversity Quotient disajikan pada tabel 7 sebagai berikut.

Tabel 6. Rangkuman Uji Normalitas Model Pembelajaran

\begin{tabular}{|c|c|c|c|c|}
\hline Model & - & Ltabel & Keputusan uji & Kesimpulan \\
\hline & & & Ltabel > Lmaks & \\
\hline $\begin{array}{l}\text { Tipe } \\
\text { TGT } \\
\text { dengan } \\
\text { media } \\
\text { Ular } \\
\text { Tangga }\end{array}$ & 0,1582 & 0,1658 & $\mathrm{H}_{\ominus}$ Diterima & $\begin{array}{c}\text { Berdistribusi } \\
\text { Normal }\end{array}$ \\
\hline $\begin{array}{l}\text { Tipe TGT } \\
\text { dengan } \\
\text { media } \\
\text { Question } \\
\text { Card } \\
\end{array}$ & 0,1402 & 0,1591 & $\mathrm{H}_{\ominus}$ Diterima & $\begin{array}{c}\text { Berdistribusi } \\
\text { Normal }\end{array}$ \\
\hline \multicolumn{5}{|c|}{ Tabel 7. Rangkuman Uji Normalitas Adversity Quotient } \\
\hline $\begin{array}{l}\text { Adversity } \\
\text { Quotient }\end{array}$ & $\frac{1}{\cos s}$ & Ltabel & $\begin{array}{l}\text { Keputusan uji } \\
\text { Ltabel > Lmaks }\end{array}$ & Kesimpulan \\
\hline Climbers & 0,1734 & 0,220 & $\mathrm{H}_{\infty}^{2}$ Diterima & $\begin{array}{c}\text { Berdistribusi } \\
\text { Normal }\end{array}$ \\
\hline Campers & 0,1591 & 0,176 & $\mathrm{H}_{\mathrm{m}}^{-}$Diterima & $\begin{array}{c}\text { Berdistribusi } \\
\text { Normal }\end{array}$ \\
\hline Quitters & 0,1664 & 0,190 & $\mathrm{H}_{m}^{-}$Diterima & $\begin{array}{l}\text { Berdistribusi } \\
\text { Normal }\end{array}$ \\
\hline
\end{tabular}

Hasil analisis uji homogenitas menggunakan uji-F untuk kelas eksperimen 1 (X MIA 4) dan kelas eksperimen 2 (X MIA 1) dengan taraf signifikansi $\alpha=5 \%$, ditunjukkan pada tabel berikut.

Tabel 8 Rangkuman Uji Homogenitas

\begin{tabular}{|c|c|c|c|c|c|}
\hline Kelas & $\begin{array}{l}t^{2} \\
s^{2}\end{array}$ & Finemg & Diatud & $\begin{array}{c}\text { Keputusan uji } \\
F_{\text {hitung }}<F_{\text {tabel }}\end{array}$ & kesimpulan \\
\hline $\begin{array}{c}\text { Eksperimen } \\
1 \\
\end{array}$ & 45,105820 & \multirow{2}{*}{1,6759} & \multirow{2}{*}{1,88} & \multirow{2}{*}{${ }_{m}$ Diterima } & \multirow{2}{*}{$\begin{array}{l}\text { variansi } \\
\text { populasi } \\
\text { homogen }\end{array}$} \\
\hline $\begin{array}{c}\text { Eksperimen } \\
2\end{array}$ & 75,591398 & & & & \\
\hline
\end{tabular}

Hasil analisis uji homogenitas Adversity Quotient menggunakan uji bartlett dengan taraf signifikansi $\alpha=5 \%$, ditunjukkan pada tabel berikut.

Tabel 9 Rangkuman Uji Homogenitas Adversity Quotient

\begin{tabular}{|c|c|c|c|c|}
\hline Kelas & 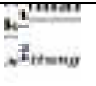 & $\frac{1}{2}$ & 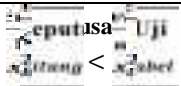 & Kesimpulan \\
\hline $\begin{array}{l}\text { Eksperimen } 1 \\
\text { dan } \\
\text { Eksperimen } 2\end{array}$ & 3,600 & 5,991 & $H_{0}$ Diterima & $\begin{array}{l}\text { variansi } \\
\text { populasi } \\
\text { homogen }\end{array}$ \\
\hline
\end{tabular}


Berdasarkan tabel tersebut berarti keputusan uji adalah terima $H_{0}$ artinya tidak terdapat perbedaan variansi antara kedua kelas (variansi populasi homogen).

Uji hipotesis yang digunakan adalah uji analisis variansi (anava) dua jalan sel tak sama dengan matriks $2 \times 3$. Tujuan analisis variansi pada penelitian ini adalah untuk menguji signifikansi efek dua variabel bebas (model pembelajaran TGT dan Adversity Quotient) terhadap satu variabel terikat (hasil belajar matematika).

Berdasarkan perhitungan analisis variansi (anava) menunjukkan bahwa nilai $\mathrm{F}_{\text {obs }}<\mathrm{F}_{\alpha} \quad$ (daerah kritis) yaitu $2,4932<4,0304\left(\mathrm{H}_{\mathrm{OA}}\right.$ diterima $)$ sehingga diperoleh suatu kesimpulan bahwa tidak terdapat perbedaan efek antara penggunaan model pembelajaran Teams Games Tournament (TGT) menggunakan media Ular Tangga dan model pembelajaran Teams Games Tournament (TGT) menggunakan media Question Card terhadap hasil belajar matematika siswa.

Hasil deskripsi data diketahui bahwa rata-rata hasil tes hasil belajar matematika pokok bahasan statistika dengan model pembelajaran Teams Games Tournament (TGT) menggunakan media Ular Tangga di kelas X MIA 4 adalah 83,9286 dan siswa yang diajar dengan model pembelajaran Teams Games Tournament (TGT) menggunakan media Question Card di kelas $\mathrm{X}$ MIA 1 adalah 80,48387, hal ini menunjukkan bahwa hasil belajar siswa yang diajar menggunakan model pembelajaran Teams Games Tournament (TGT) menggunakan media Ular Tangga tidak berbeda secara signifikan dengan hasil belajar siswa yang diajar dengan menggunakan model pembelajaran Teams Games Tournament (TGT) menggunakan media Question Card.

Kenyataan yang terjadi saat penelitian, pada pelaksanaan model pembelajaran TGT menggunakan media Ular Tangga maupun Question Card terdapat lima komponen utama yaitu Class Presentation, Teams,
Games, Tournament dan Teams Recognition. Perbedaannya terdapat pada cara permainan dalam Tournament masing-masing media. Dimana kedua media ni dapat menbangkitkan minat siswa untuk berkompetisi atau bersaing agar memperoleh kemenangan dalam Tournament dengan cara berusaha menjawab soal dengan benar.

Penghitungan analisis variansi (anava) menunjukkan bahwa nilai $\mathrm{F}_{\mathrm{obs}}>\mathrm{F} \alpha$ yaitu $3,7166>3,1788\left(\mathrm{H}_{0 \text { в }}\right.$ ditolak $)$ dan setelah diuji lanjut pasca anava diperoleh hasil sebagai berikut.

1. Komparasi antara Adversity Quotient tipe climbers dan campers

$\mathrm{F}_{\text {ols }}<\mathrm{F} \alpha$ yaitu $1,6409<6,3577$ ( $H_{0}$ diterima)

2. Komparasi antara Adversity Quotient tipe climbers dan quitters

$\mathrm{F}_{\text {obs }}>\mathrm{F} \alpha$ yaitu $6,7532>6,3577$ $\left(H_{0}\right.$ ditolak $)$

3. Komparasi antara Adversity Quotient tipe campers dan quitters

$\mathrm{F}_{\text {ols }}<\mathrm{F} \alpha$ yaitu $2,3690<63577$ ( $H_{0}$ diterima)

sehingga diperoleh suatu kesimpulan bahwa ada perbedaan efek antara Adversity Quotient Adversity Quotient tipe climbers dan campers dan quitters dan campers dan quitters terhadap hasil belajar matematika siswa. Siswa yang memiliki Adversity Quotient tipe climbers memiliki hasil belajar yang lebih baik daripada siswa yang memiliki Adversity Quotient tipe quitters baik kelas yang diajar dengan model pembelajaran TGT menggunakan media Ular Tangga maupun Question Card. Hasil belajar siswa yang memiliki Adversity Quotient tipe climbers tidak jauh berbeda dengan hasil belajar siswa yang memiliki Adversity Quotient tipe campers, begitu juga dengan hasil belajar siswa yang memiliki Adversity Quotient tipe campers tidak jauh berbeda dengan siswa yang memiliki Adversity Quotient tipe quitters.

Hasil perhitungan analisis variansi (anava) menunjukkan bahwa nilai $\mathrm{F}_{\mathrm{obs}}>\mathrm{F} \alpha$ yaitu $1,0669>3,1788\left(\mathrm{H}_{0 \mathrm{AB}}\right.$ diterima $)$ 
sehingga dapat ditarik suatu kesimpulan tidak terdapat interaksi antara model pembelajaran Teams Games Tournament (TGT) menggunakan media Ular Tangga dan Question Card dengan Adversity Quotient tipe climbers, campers, dan Quitter terhadap hasil belajar matematika siswa.

\section{KESIMPULAN DAN SARAN \\ Simpulan}

Berdasarkan hasil analisis dan pembahasan yang telah dilakukan, maka peneliti mengambil beberapa kesimpulan sebagai berikut.

1. Model pembelajaran Teams Games Tournament (TGT) menggunakan media Ular Tangga sama efektifnya dengan model pembelajaran Teams Games Tournament (TGT) menggunakan media Question Card terhadap hasil belajar matematika siswa.

2. Terdapat pengaruh antara Adversity Quotient kategori climbers, campers, dan quitters terhadap hasil belajar matematika siswa. Siswa yang memiliki Adversity quotient kategori climbers memperoleh nilai hasil belajar yang lebih baik daripada siswa yang memiliki Adversity Quotient kategori Quitter. Siswa yang memiliki Adversity Quotient kategori climbers dan Adversity Quotient campers memperoleh nilai hasil belajar yang sama. Di sisi lain siswa yang memiliki Adversity Quotient kategori campers dan Adversity Quotient kategori quitters memperoleh nilai hasil belajar yang sama.

3. Tidak terdapat interaksi antara model pembelajaran TGT menggunakan media Ular Tangga dan Question Card dengan Adversity Quotient tipe climbers, campers, dan quitter terhadap hasil belajar matematika.

\section{Saran}

1. Bagi Siswa

Pembelajaran menggunakan model pembelajaran Teams Games Tournament
(TGT) menggunakan media Ular Tangga atau Question Card dapat diterapkan pada kegiatan pembelajaran agar siswa lebih menyukai matematika dan menjadi bersemangat dalam kegiatan pembelajaran sehingga membuka wacana siswa bahwa belajar matematika itu menyenangkan dan tidak membosankan.

2. Bagi Sekolah

Penerapan model pembelajaran Teams Games Tournament (TGT) menggunakan media pembelajaran hendaknya dapat dijadikan sebagai bahan pertimbangan untuk meningkatkan hasil belajar matematika.

3. Bagi Guru Matematika

a. Guru hendaknya mencoba menerapkan model pembelajaran Teams Games Tournament (TGT) menggunakan media Ular Tangga atau Question Card agar dapat meningkatkan keefektivan pembelajaran sehingga hasil belajar matematika menjadi meningkat.

b. Guru perlu mengembangkan media pembelajaran yang inovatif pada materi pembelajaran statistika agar dapat diserap siswa secara optimal.

4. Bagi Peneliti

Bagi peneliti selanjutnya yang ingin meneliti lebih lanjut mengenai pembelajaran model koperatif tipe TGT (Teams Games Tournaments) menggunakan media Ular Tangga atau Questions Card agar lebih memperhatikan kelemahan-kelemahan dalam pembelajaran ini sehingga dapat diperoleh hasil yang lebih baik.

\section{DAFTAR PUSTAKA}

Arifin, Z. 2012. Penelitian Pendidikan Metode dan Paradigma Baru. Bandung: Remaja Rosdakarya.

Christano, R. 2013. Pengaruh Penerapan Model Pembelajaran Kooperatif Tipe Teams Games Tournament terhadap Hasil Belajar Siswa Mata Pelajaran TIK Kelas X di SMA Negeri 1 Piyungan 
Tahun Ajaran 2012/2013, (Online), (http://eprints.uny.ac.id, Di unduh 06 Maret 2015).

Aulia, A. (2014). Pengaruh Adversity Quotient (AQ) dan Motivasi Belajar terhadap Hasil Belajar pada Mata Pelajaran Ekonomi (Survei pada Kelas XI IPS se-Kota Bandung) Tahun Ajaran 2013/2014), (Online), (http://repository.upi.edu, Diunduh 06 Maret 2015).

Febrina, A. 2013. Pengaruh Model Pembelajaran Kooperatif Tpe TGT Berbantuan Kartu Soal Terhadap Hasil Belajar Siswa pada Materi Pokok Bunyi Kelas VIII SMP Negeri 3 Percut Sei Tuan. Jurnal INPAFI, (Online), Vol. 1, No. 2, (http://jurnal.unimed.ac.id, Diunduh 06 Maret 2015).

Prasetyaningrum, D. 2013. Studi Komparasi Metode Pembelajaran teams Games Tournament (TGT) disertai Media Kartu Soal dan Roda Impian terhadap Prestasi Belajar Siswa pada Materi Hidrokarbon Kelas SMA NEGERI 7 SURAKARTA Tahun Pelajaran 2012/2013, (online), (http://eprints.uns.ac, Diunduh 27 Februari 2015).

Pratiwi, A. (2012). Pengaruh Permainan dan Motivasi Anak Terhadap Penguasaan Konsep Matematika Anak Usia Dini. Jurnal Pendidikan, 18(2):106 - 121.

Sam, M. 2013. Efektivitas Media Ular Tangga pada Pembelajaran Kimia Berbasis Kooperatif Tipe TGT terhadap Sikap Komunkatif dan Kerja Sama serta Hasil Belajar Siswa pada Pokok Bahasan Hidrokarbon. (Online), (htt[://digilib.unimed.ac.id, Diunduh 27 Februar 2015).

Sudarman. 2012. Adversity Quotient: Kajian Kemungkinan Pengintegrasinya dalam Pembelajaran Matematika. Aksiomma, (Online), Vol. 1, No. 1, (http://Jurnal.untad.ac.id, Diunduh 24 Februari).
Sundayana, R. 2014. Media dan Alat Peraga Pembelajaran Matematika. Bandung: Alfabeta.

Taniredja, T. dkk. 2013. Model-model Pembelajaran Inovatif dan Efektif. Bandung: Alfabeta 